\title{
LEUNIG regulates AGAMOUS expression in Arabidopsis flowers
}

\author{
Zhongchi Liu and Elliot M. Meyerowitz \\ Biology, 156-29, California Institute of Technology, Pasadena, CA 91125, USA
}

\section{SUMMARY}

LEUNIG was identified in a genetic screen designed to isolate second-site enhancer mutations of the floral homeotic mutant apetala2-1. leunig mutations not only enhance apetala2, but by themselves cause a similar but less-pronounced homeotic transformation than apetala2 mutations. leunig flowers have sepals that are transformed toward stamens and carpels, and petals that are either staminoid or absent. In situ hybridization experiments with leunig mutants revealed altered expression pattern of the floral homeotic genes APETALA1, APETALA3, PISTIL-
LATA, and AGAMOUS. Double mutants of leunig and agamous exhibited a phenotype similar to agamous single mutants, indicating that agamous is epistatic to leunig. Our analysis suggests that a key role of $L E U N I G$ is to negatively regulate $A G A M O U S$ expression in the first two whorls of the Arabidopsis flower.

Key words: Arabidopsis, floral homeotic mutants, leunig, cadastral gene

\section{INTRODUCTION}

A fundamental question in plant development is that of how a multipotential cell becomes committed to a specific fate. Using Arabidopsis flower development as our model system, we have begun to understand how a group of undifferentiated cells in a floral meristem develop into a complex floral structure with four types of floral organs and many different cell types. Such a complex developmental process employs many regulatory genes with functions analogous to those involved in animal development. Floral homeotic genes (Bowman et al., 1989; Weigel and Meyerowitz, 1994), which are required to specify four types of floral organ identities, are similar to the homeotic selector genes that specify segment identity in flies (Lewis, 1978; Akam, 1987; Ingham, 1988). Genes that set the boundaries of floral homeotic gene function are analogous to the gap genes of flies (Reinitz and Levin, 1990), and are referred to as cadastral genes (Bowman et al., 1992; Weigel and Meyerowitz, 1994). This paper reports the identification and characterization of a novel cadastral gene, LEUNIG $(L U G)$, in Arabidopsis flower development.

Arabidopsis thaliana flowers consist of four whorls of organs: 4 sepals, 4 petals, 6 stamens and 2 fused carpels arranged from the outermost (whorl 1) to the innermost (whorl 4) (Fig. 1A, B). A model has been established to account for how four different floral organ types are specified by region-specific activities of three classes (A, B, C) of floral homeotic genes (reviewed by Coen and Meyerowitz, 1991; Weigel and Meyerowitz, 1994). Class A genes are active in whorls 1 and 2 and are required for sepal and petal development. Class $\mathrm{C}$ genes act in whorls 3 and 4 and are required to specify stamen and carpel development. Class B genes function in whorls 2 and 3. In combination with class A genes, they specify petal development in whorl 2 and, along with the $\mathrm{C}$ genes, stamen development in whorl 3 .
In Arabidopsis, described class A genes include APETALA1 $(A P 1)$ and APETALA2 (AP2), class B genes are APETALA3 (AP3) and PISTILLATA (PI), and the known class $\mathrm{C}$ gene is AGAMOUS (AG). All of these genes have been cloned (Yanofsky et al., 1990; Jack et al., 1992; Mandel et al., 1992; Goto and Meyerowitz, 1994, Jofuku et al., 1994). AP1, AG, AP3, and PI proteins all contain a conserved protein domain, the MADS domain, which is found in transcription factors in organisms ranging from yeast (MCM1, Passmore et al., 1988) to human (SRF, Norman et al., 1988). With gene-specific probes, the expression pattern of these four floral homeotic genes has been analyzed using in situ hybridization. Their RNA distribution largely coincides with the domain of their function. One class A gene, $A P 1$, is expressed in whorls 1 and 2 in stage 3 and older flowers, although it is initially expressed in the entire floral primordium (Gustafson-Brown et al., 1994); the class B genes AP3 and PI are largely expressed in whorls 2 and 3, although $P I$ is initially expressed in whorls 2, 3 and 4 (Jack et al., 1992; Goto and Meyerowitz, 1994); the C class gene $A G$ is expressed in whorls 3 and 4 (Drews et al., 1991).

At the molecular level, AP2 is unique among these genes in that it does not encode a MADS box but rather a novel, putatively nuclear protein with two 68-amino acid repeat motifs (Jofuku et al., 1994). Despite its domain-specific function in whorls 1 and 2 (Kunst et al., 1989; Bowman et al., 1991), AP2 RNA is detected in all four whorls of a flower as well as in vegetative tissues (Jofuku et al., 1994). Thus the domainspecific function of $A P 2$ may be conferred by domain-specific translational or post-translational controls, or by interaction with other domain-specific factor(s).

How is the domain of the A, B and C activities established? In Arabidopsis, meristem identity genes $L F Y$ and $A P I$ initiate floral development by activating floral homeotic gene expression in the floral meristem (Weigel et al., 1992; Weigel 
and Meyerowitz, 1993; Bowman et al., 1993). The cadastral genes act next to define the boundaries of homeotic gene expression and function. For example, SUPERMAN (SUP) in Arabidopsis acts to prevent B class genes from functioning in whorl 4, and is therefore a cadastral gene (Bowman et al., 1992). The correct temporal and spatial pattern of B class gene expression and function is therefore controlled by the combined action of positive regulators $L F Y$ and $A P I$ and the negative regulator $S U P$.

The class A gene $A P 2$ and the class $\mathrm{C}$ gene $A G$ are also cadastral genes because they are involved in establishing the boundary between $\mathrm{A}$ and $\mathrm{C}$ activities. These two genes negatively regulate each other, and as a result, the A function is restricted to whorls 1 and 2 , and the $\mathrm{C}$ function is restricted to whorls 3 and 4 (Bowman et al., 1991). In ap2 loss-of-function mutants, $A G$ activity expands into whorls 1 and 2, causing the formation of carpels in whorl 1 and stamens in whorl 2. In $a g$ loss-of-function mutants, $A P 1$ and $A P 2$ organ identity functions expand into whorls 3 and 4 , resulting in the conversion of stamens to petals, and carpels to sepals. This cadastral activity of $A P 2$ and $A G$ is also revealed at the molecular level by in situ RNA hybridization. In $a g$ mutants, $A P l$ RNA expands to all whorls instead of being present only in whorls 1 and 2 (Gustafson-Brown et al., 1994); in ap2-2 mutants, $A G$ RNA is present in all whorls instead of only in whorls 3 and 4 (Drews et al., 1991). Since AP2 RNA is distributed in all four whorls, the spatially restricted cadastral activity of $A P 2$ must depend on additional domain-specific cadastral factor (s) for $A G$ repression. $A P 1$ is not such a factor because loss of $A P 1$ does not result in ectopic $A G$ RNA expression (Gustafson-Brown et al., 1994).

To identify additional genes involved in $A G$ regulation, we undertook a genetic screen for second-site enhancer or suppressor mutations of a weak ap2 allele, ap2-1 (Bowman et al., 1989). In ap2-1, whorl 1 organs are leaves instead of sepals; whorl 2 petals are staminoid; and whorl 3 and 4 organs are normal (Fig. 1C; Bowman et al. 1989, 1991). The ap2-1 phenotype is very different from that of strong ap2 mutants (Fig. 1D), and this difference results from intact or partially intact cadastral activity still present in the ap2-1 mutants (Drews et al., 1991; Bowman et al., 1991). In this screen, we isolated two mutations that define a second-site enhancer of ap2-1, named LEUNIG (LUG). Although our lug mutations were found to be allelic to a mutation in strain $\mathrm{Fl}$-89, previously thought primarily to affect carpel fusion (Komaki et al., 1988), the enhancer screen has revealed an additional role of $L U G$ in floral organ specification. The analysis of lug mutants reported here indicates that $L U G$ is a cadastral gene involved in A and $\mathrm{C}$ boundary establishment during Arabidopsis flower development.

\section{MATERIALS AND METHODS}

\section{Genetics}

ap2-1 homozygous seeds were washed in $0.1 \%$ Tween-20 for 15 minutes, subsequently mutagenized with $0.1 \%$ EMS (ethylmethane sulfonate) for 8 hours, then washed with sterile water several times for a total of 4.5 hours, and sown on soil mix. 5,000 M1 plants germinated and gave rise to M2 seeds. The use of such a low concentration of EMS is based on our observation that ap2-1 seeds are more susceptible to EMS than wild-type seeds. $42 \%$ of the mutagenized M1 plants possessed siliques segregating one-quarter embryonic lethals.
M2 seeds were collected as families (10 M1 plants per family). Approximately 120 M2 plants were screened per family. 334 families out of the 500 families were screened.

The isolated enhancer mutants were crossed into wild-type Landsberg erecta: (L-er) plants, and all $\mathrm{F}_{1}$ progeny were wild-type, indicating that both the ap2-1 and the enhancer mutations are recessive to wild-type. For extragenic enhancers, the $\mathrm{F}_{2}$ progeny segregated both ap $2-1$ and the enhancer mutations. For intragenic ap 2 enhancers, ap2-1 plants were not recovered in the $\mathrm{F}_{2}$ generation.

Two independent lug mutations were obtained from screening progeny of $3340 \mathrm{M} 1$ plants. The frequency of mutations in the $L U G$ gene was thus roughly 1 in $1670 \mathrm{M} 1$ plants. This is probably an underestimate, because at least one more leunig-like mutant was identified and then lost due to poor fertility.

The map location of lug was determined by its linkage to ap2 and $a g$ on chromosome 4 . According to the frequency of recombination between $a p 2$ and $l u g$ and between $a g$ and $l u g$, lug is situated between ap2 and ag 16 map units above ap2 and 14 map units below ag (data not shown).

ap2-9 lug-1 double mutants were constructed by crossing homozygous ap 2-9 (L-er) pollen to lug-1 (L-er) carpel to generate $\mathrm{F}_{1}$ transheterozygotes. Twenty lug- 1 single mutant plants in the $\mathrm{F}_{2}$ generation were selfed and planted as individual families. 2 such lug-1 plants segregated plants with three different phenotypes: (A) lug-1 single mutant phenotype; (B) ap2-9 lug-1 double mutant phenotype; (C) an intermediate phenotype between class $\mathrm{A}$ and $\mathrm{B}$. To confirm that the class C represents lug-1 plants heterozygous for ap2-9, seeds from individual plants in class A and C were collected (class B is completely sterile). Class C plants all segregated ap2-9 lug-1 double mutants; whereas class A did not segregate any ap2-9 lug-1.

\section{Scanning electron microscopy}

Samples were collected, fixed, coated, and photographed as described previously (Bowman et al., 1989, 1991).

\section{In situ hybridization}

For radioactive in situ hybridization, all flowers were collected, fixed, embedded, sectioned, and hybridized as described previously (Drews et al., 1991).

For non-radioactive in situ hybridization (Fig. 4), the fixation, embedding and sectioning steps were essentially the same as for radioactive hybridizations except that the fixation step was shorter (1 hour) and the time between infiltration steps was minimized. The probes were synthesized using the DIG (digoxigenin) RNA labeling kit (Boehringer Mannheim Biochemical) according to the manufacturer's instructions. Slide treatment before hybridization was similar to that of radioactive in situ hybridization. Subsequent hybridization, wash, signal detection steps were modifications of Langdale et al. (1987).

Antisense probes were made from pCIT 565 for $A G$ (Yanofsky et al., 1990), pAM 128 for AP1 (Mandel et al., 1992), pD793 for AP3 (Jack et al., 1992), and pcPINX for PI (Goto and Meyerowitz, 1994).

\section{Image processing}

Negatives and slides were scanned and digitized using a Nikon Coolscan. Brightness and contrast were adjusted using Adobe Photoshop 3.0, and for the in situ double exposures, the color balance was similarly adjusted. Final figures were printed using a Kodak XLS 8300 Digital Printer.

\section{Plant growth}

Seeds were sown in a 1:1:1 mixture of perlite:vermiculite:soil, incubated at $4^{\circ} \mathrm{C}$ for 4 days, and then placed under lights. Biological larvicide Gnatrol (Abbott Laboratory) was added to the water used to moisten the soil mixture before sowing. Unless otherwise noted, all plants were grown under $600 \mathrm{ft}$-candles of constant cool white fluorescent light at $22-24^{\circ} \mathrm{C}$. Plants were fertilized at about 10 days after germination with Plantex all purpose fertilizer. 


\section{RESULTS}

\section{Identifying leunig}

About 5,000 M1 ap2-1 seeds germinated after the EMS (ethylmethane sulfonate) treatment, and about 27,400 M2 ap2-1 plants, representing 3340 M1 plants, were screened to identify mutations that cause either a suppressed phenotype resembling wild-type, or an enhanced phenotype resembling strong ap2 mutants. Thirteen putative enhancer mutations with phenotypes resembling strong ap2 mutants were identified (Fig.
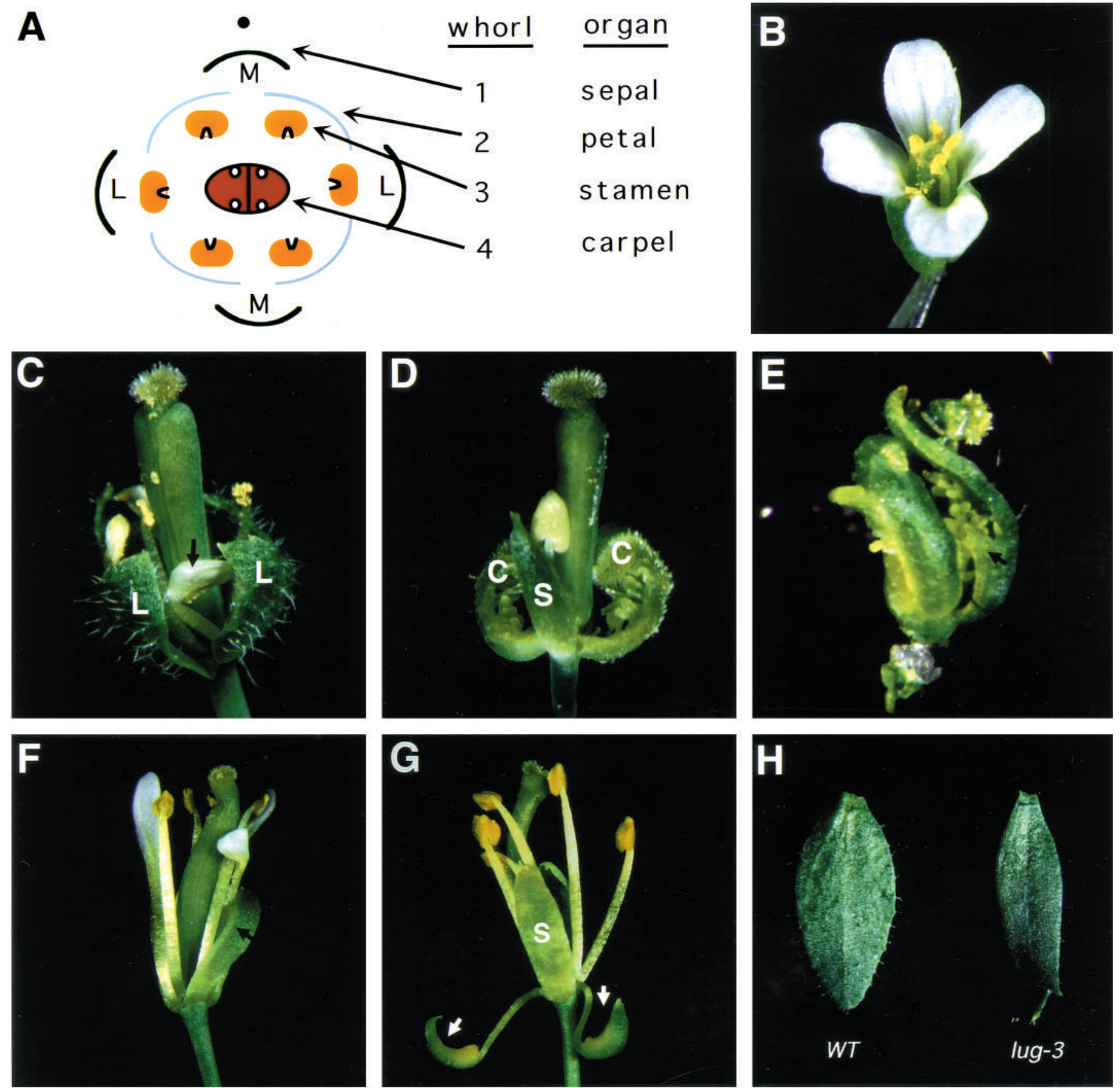

Fig. 1. Structure and phenotypes of wild-type and mutant Arabidopsis flowers. (A) A diagram of a wild-type Arabidopsis flower. The black dot indicates the inflorescence meristem (IM). Abbreviations are: M, medial position with respect to IM; L, lateral position with respect to IM. The medial adaxial sepal is adjacent to IM, and the medial abaxial sepal is opposite to IM. (B) A wild-type Arabidopsis flower. (C) An ap2-1 flower with leaves (L) in whorl 1, staminoid petals (arrow) in whorl 2, and normal stamens and carpels in whorls 3 and 4. (D) An ap2-2 flower with medial carpels (C) and lateral sepals (S) in whorl 1. Whorl 2 and 3 organs are reduced to a single stamen. (E) An ap2-1 lug-1 flower with medial whorl 1 carpels (arrow) and whorl 4 unfused carpels. Lateral whorl 1 organs, and whorl 2 and 3 organs are absent. (F) A basal lug- 1 flower with narrow floral organs. The thickening of the sepal edge (black arrow) indicates slight carpelloidy. (G) An apical lug-1 flower. Medial whorl 1 sepals are staminoid (arrows), lateral whorl 1 sepals (S) are normal, and whorl 2 petals are absent. (H) Cauline leaves of wild-type (WT, L-er ecotype) and lug-3. 
1E); however, no suppressor mutations were isolated. Segregation tests established that only two of the 13 enhancer mutations are second-site mutations and the remaining 11 appear to be intragenic ap2 mutations (see Materials and Methods).

The two second-site enhancer mutations are recessive, exhibit similar phenotypes, and fail to complement each other, thus defining a single genetic locus. This locus was mapped to chromosome 4 (see Materials and Methods). The two mutations were subsequently shown to be allelic to two mutations previously isolated by D.R. Smyth in our laboratory, called leunig (lug) and to a mutation in a strain named $\mathrm{Fl}-89$ (Komaki et al., 1988). Several new lug alleles were later obtained (Table 1).

\section{Morphological characterization of lug mutants}

We have analyzed a total of 10 alleles of lug (Table 1), all of which cause similar recessive phenotypes. First of all, lug mutants are characterized by narrow leaves and floral organs (Fig. 1F-H). Secondly, homeotic transformation in floral organ identity is frequently observed in whorls 1 and 2 (see below). Thirdly, reduction in organ number occurs frequently in whorls 2 and 3 (Fig. 1F,G). Finally, whorl 4 carpels fail to fuse properly (below). The defects in floral organ identity and floral organ number are more severe in flowers arising later in an inflorescence shoot, that is in a more apical position (Fig. 1 compare $\mathrm{F}$ and $\mathrm{G}$ ). Thus it is important to distinguish "earlyarising" (basal) flowers (Fig. 1F) from "late-arising" (apical) flowers (Fig. 1G) on the same inflorescence. When we examined young inflorescences of lug- 1 by scanning electron microscopy (SEM), the flower primordia appear normal (Fig. 2, compare A to F), however, the floral organ primordia are narrow in lug. In old inflorescences of lug- 1 (Fig. 2G), flower primordia are abnormal in shape. In more apical flowers, the size of the center dome interior to whorl 1 organs is much reduced (Fig. 2L, Q), thus insufficient central primordial cells may be responsible for the reduced number of floral organs in more apical lug flowers. Specific effects of lug on each whorl are described in detail below.

Table 1. Sources of lug alleles

\begin{tabular}{lcccl}
\hline Allele* & Isolation no. & Mutagen & Effect $\dagger$ & Origin \\
\hline 1 & 38 & EMS & Intermediate & Present study \\
2 & 70 & EMS & Strong & Present study \\
3 & $68-2$ & EMS & Strong & G. Fox and T. Jack \\
$4^{\mathrm{a}}$ & $60-2$ & EMS & Strong & G. Fox and T. Jack \\
5 & $1-4$ & EMS & Strong & J. Levin \\
6 & 2 B11 & EMS & Intermediate & D. Weigel \\
7 & Morph 3 & EMS & ND & S. Jacobsen \\
8 & S24 & EMS & Weak & D. Smyth \\
9 & S42 & EMS & Weak & D. Smyth \\
10 & Fl-89 & EMS & Weak & K. Okada $\ddagger$
\end{tabular}

\footnotetext{
*All alleles were induced in Lansberg erecta background.
}

†"weak", "intermediate", and "strong" alleles are classified according to how soon an inflorescence gives rise to flowers that exhibit reduced number of petals and carpelloid/staminoid sepals. Stronger mutations exhibit defects sooner than weaker alleles. In flowers at more apical positions, different alleles exhibit similar phenotypes.

$\ddagger$ Komaki et al., 1988 .

$4^{\mathrm{a}}$ : this allele exhibits mosaic whorl 1 organs at a high frequency.

\section{Whorl 1 effects}

Partial homeotic transformation is frequently observed in whorl 1. Whorl 1 sepals are frequently petaloid, staminoid or carpelloid (Fig. 2, compare B-D with H-J, M and N; Table 2). In basal flowers, whorl 1 medial positions can be occupied by sepals with petaloid tissue at their margins (Fig. 2H). In apical flowers, whorl 1 medial organs can be staminoid or carpelloid (Fig. 2I,J,M), or stamen/carpel mosaics with ovules developing along the margins of the mosaic organs (Table 2; data not shown). The medial adaxial sepal is more transformed than the medial abaxial sepal. Lateral whorl 1 organs are less affected

Fig. 2. Scanning electron microscopic (SEM) pictures of wild-type and $l u g$ single mutants. Bars equal $10 \mu \mathrm{m}$ in A-D, F-L, O-R; bars equal $100 \mu \mathrm{m}$ in $\mathrm{E}, \mathrm{M}, \mathrm{N}, \mathrm{R}, \mathrm{S}$. Numbers indicate the stages of respective flowers according to Smyth et al. (1990). Abbreviations are: IM, inflorescence meristem; s, sepal; P, petal; st, stamen; C, carpel or carpelloid; st/s, staminoid sepal; o, ovule; H, horn-like; F, filament; $\mathrm{sb}$, stigmatic bundle. (A) A wild-type inflorescence.

(B) Close-up of wild-type sepal tissues. Note the sepal-specific long cells and the stoma (arrow). (C) Close-up of wild-type petal cells at stage 11. (D) Close-up of mature wild-type stamen anther cells. (E) Top view of a fused wild-type carpel at stage 11. (F) A young lug-1 inflorescence which is similar to wild-type with the exception of narrow floral organ primordia. (G) An old lug-1 inflorescence. Note the abnormal shape of each floral primordium. In the stage 5 flower, the asterisk $(*)$ indicates a whorl 2 organ, which is located abnormally inbetween the whorl 1 organs and may fuse with the whorl 1 organs. The arrow points to the absence of stamen and petal primordia in the stage 5 flower (compared with $\mathrm{K}$ ). (H) Close-up of a lug-4 whorl 1 organ mosaic for petal (P) and sepal (s) tissues. (I) Close-up of a lug-2 whorl 1 organ mosaic for stamen (st) and sepal (s) tissues. (J) Close-up of a lug-2 whorl 1 organ mosaic for carpel and sepal (s) tissues. Note the two ovules (o) developing from the margin. (K) A stage 5 wild-type flower. Two whorl 1 sepals have been removed to reveal the stamen (st) and petal (arrow) primordia. (L) An apical lug-2 stage 4 flower. Note the much reduced central dome (compared with the stage 4 flower in A). (M) A lug-l flower dissected to reveal the similarity of a carpelloid whorl 1 organ to the whorl 4 carpel (C). Note the presence of carpel-specific characters in the whorl 1 organ: stigmatic tissue (black arrow) and the ovules (white arrows). (N) A lug-2 flower with whorl 1 medial carpels, whorl 1 lateral staminoid sepals (st/S). Ovules (black arrows) are visible near the base of whorl 1 carpels. The narrow and elongated tips (white arrows) of whorl 1 carpels resemble the horn-like protrusions of lug carpels (see T). (O) An unfused carpel of lug-2. One of the carpels is filament-like (F). The ovules developing from the placenta appear normal at this stage. (P) A dissected stage 7 wildtype flower. All sepals have been removed showing petal (P) stamen (st), and carpel (C) primordia. (Q) An apical lug-2 stage 6 flower. The two medial carpelloid sepals (s) are dissected away, so are the two lateral filamentous sepals (arrows). Note the much reduced central primordium and the absence of stamen and petal primordia (compared with P). Fusion may occur between the two medial whorl 1 organs and the inner organs (most likely, with the whorl 4 carpels). (R) A whorl 2 mosaic organ in lug-4 with petal (P) blade on top and a stamen filament (F) at the base. (S) A lug-2 flower with an abnormally developing stamen. Note the asynchronous development of the two anther thecae (arrows). This stamen is flanked by a filament (F) and an unfused whorl 4 carpel (C). (T) An unfused gynoecium of lug-3 showing the two horn-like (H) protrusions and the two unfused stigmatic bundles (sb). The two horns are extensions of the carpel valves, and the stigmatic bundles grow out of the septum region. 
LEUNIG regulates AGAMOUS
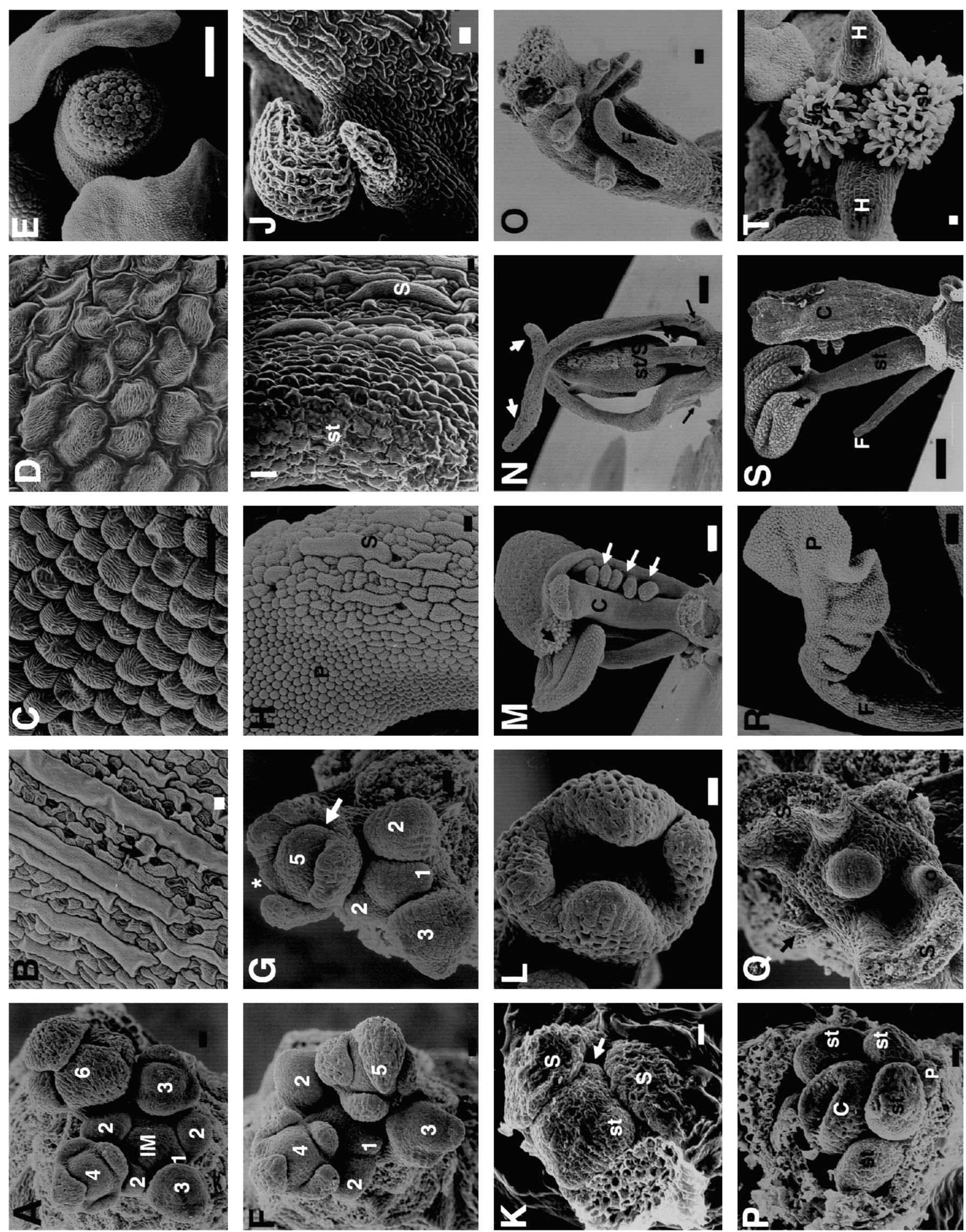
Table 2. Comparison of organ types in lug-1 mutant and wild-type flowers

\begin{tabular}{|c|c|c|c|c|c|c|}
\hline \multirow[b]{2}{*}{ Whorl } & \multirow[b]{2}{*}{$\begin{array}{c}\text { Position } \\
\text { (organ number) }\end{array}$} & \multirow[b]{2}{*}{ Organ identity } & \multirow[b]{2}{*}{$\begin{array}{c}\text { Wild type* } \\
\%\end{array}$} & \multicolumn{3}{|c|}{ lug-1 } \\
\hline & & & & $\begin{array}{c}1-10(29) \dagger \\
\%\end{array}$ & $\begin{array}{c}11-20(25) \dagger \\
\%\end{array}$ & $\begin{array}{c}21-30(21) \dagger \\
\%\end{array}$ \\
\hline \multirow[t]{12}{*}{1} & Medial & Sepals & 100 & 60 & 10 & 0 \\
\hline & (2) & Staminoid & 0 & 17 & 52 & 57 \\
\hline & & Petaloid & 0 & 10 & 8 & 0 \\
\hline & & $\mathrm{St} / \mathrm{Ca} \ddagger$ & 0 & 5 & 14 & 36 \\
\hline & & St/Pet $\neq$ & 0 & 5 & 0 & 0 \\
\hline & & Carpelloid & 0 & 1 & 6 & 7 \\
\hline & & Absent & 0 & 0 & 2 & 0 \\
\hline & Lateral & Sepals & 100 & 96 & 48 & 17 \\
\hline & (2) & Petaloid & 0 & 3 & 52 & 38 \\
\hline & & Staminoid & 0 & 0 & 0 & 2 \\
\hline & & Caplloid & 0 & 0 & 0 & 23 \\
\hline & & Others & 0 & 0 & 0 & 20 \\
\hline \multirow[t]{3}{*}{2} & (4) & Petals & 100 & 47 & 15 & 6 \\
\hline & & Staminoid & 0 & 9 & 5 & 0 \\
\hline & & Absent & 0 & 42 & 78 & 94 \\
\hline \multirow[t]{3}{*}{3} & (6) & Stamens & 99 & 66 & 54 & 49 \\
\hline & & Filaments & 0 & 0.5 & 0 & 2 \\
\hline & & Absent & 1 & 33 & 46 & 49 \\
\hline \multirow[t]{3}{*}{4} & (2) & $<2$ Carpels & 0 & 17 & 12 & 14 \\
\hline & & 2 Carpels & 100 & 76 & 80 & 86 \\
\hline & & $>2$ Carpels & 0 & 7 & 8 & 0 \\
\hline
\end{tabular}

*From Smyth et al., 1990.

$\dagger$ The numbers 1-10,11-20, and 21-30 indicate the positions of the flowers in an inflorescence with $1=$ most basal position; the numbers in the parentheses indicate the number of flowers scored.

$\ddagger$ St/Ca:staminoid carpel; St/Pet: staminoid petal; Pet/Ca: petaloid carpel. Also see Bowmen et al. (1991).

by lug mutations than medial ones, as is also true of ap2-2 mutants (Fig. 1D; Bowman et al., 1991). The lateral whorl 1 organs can develop into sepals, petaloid sepals, staminoid sepals, carpelloid sepals or filaments (Figs 1G, 2N; Table 2). Frequently, carpelloid sepals of lug mutants lack stigmatic tissues, are much elongated, and exhibit horn-like protrusions at the tips characteristic of whorl 4 lug carpels (Fig. 2N,T).

\section{Whorl 2 effects}

Homeotic transformation is observed in whorl 2 petals with stamen characteristics: stamen-like filaments at the base (Fig. $2 \mathrm{R}$ ) or anther tissue at the top (data not shown). In addition, lug flowers have a reduced number of petals in whorl 2 , especially in apical flowers (Table 2; Fig. 1F,G). Loss of petals likely results from the fact that the central dome is much reduced in size (Fig. 2L,Q). Thus, insufficiency of central primordial cells may be responsible for the reduction in floral organ initiation. Fusion between whorl 2 organs and whorl 1 organs, although rarely observed, may also account for some of the reduced petal number (see Fig. $2 \mathrm{G}$ and legend).

\section{Whorl 3 effects}

In lug mutants, stamens are reduced in number (Table 2), presumably due to the reduction of stamen primordium initiation (Fig. 2; compare G, L, Q to A (stage 4), K (stage 5), and P (stage 7)). Occasionally, anthers senesce prematurely or are malformed (Fig. 2S).

\section{Whorl 4 effects}

The number of whorl 4 carpels in lug flowers varies from 1.5 (with one fully developed and one half-developed carpel) to 4
(Table 2). The reduction in carpel number results from early abortion, filamentous growth or retarded development of one or both of the carpels (Fig. 2O). Increase in carpel number, however, is attributed to additional filamentous organs fused at the base of carpels at medial positions and thus may merely reflect an artificial assignment.

In almost every lug flower, the carpels fail to fuse properly (compare Fig. 2T and E). We frequently observed horn-like protrusions at the tip of each carpel valve as well as two stigmatic bundles topping two septum tissues (Fig. 2T; Komaki et al., 1988). Wild-type pollen does not rescue low female fertility of lug mutants, indicating possible defects in ovule development and/or septum transduction for pollen tube growth.

\section{lug mutations cause ectopic B and C homeotic gene expression}

According to the ABC model (reviewed by Weigel and Meyerowitz, 1994), the homeotic transformation observed in whorls 1 and 2 of $l u g$ flowers suggests that both C and B class genes are ectopically active. Since the RNA expression pattern of both $\mathrm{C}$ and $\mathrm{B}$ class genes correlates with their functions (Drews et al., 1991; Jack et al., 1992; Goto and Meyerowitz, 1994), we sought to examine the RNA expression pattern of $A G, A P 3$, and $P I$ in $l u g$ mutants by use of in situ hybridization.

\section{Expression of the $\mathrm{C}$ class gene $A G$}

Both the temporal and the spatial pattern of $A G$ expression is altered in lug flowers (Fig. 3). In flowers of wild-type, ap2-1 (Drews et al., 1991), and apl-1 (Fig. 3D; Gustafson-Brown et al., 1994), $A G$ RNA is not detected in stage 1 and stage 2 floral primordia; a low level of $A G$ RNA starts in the center of early 

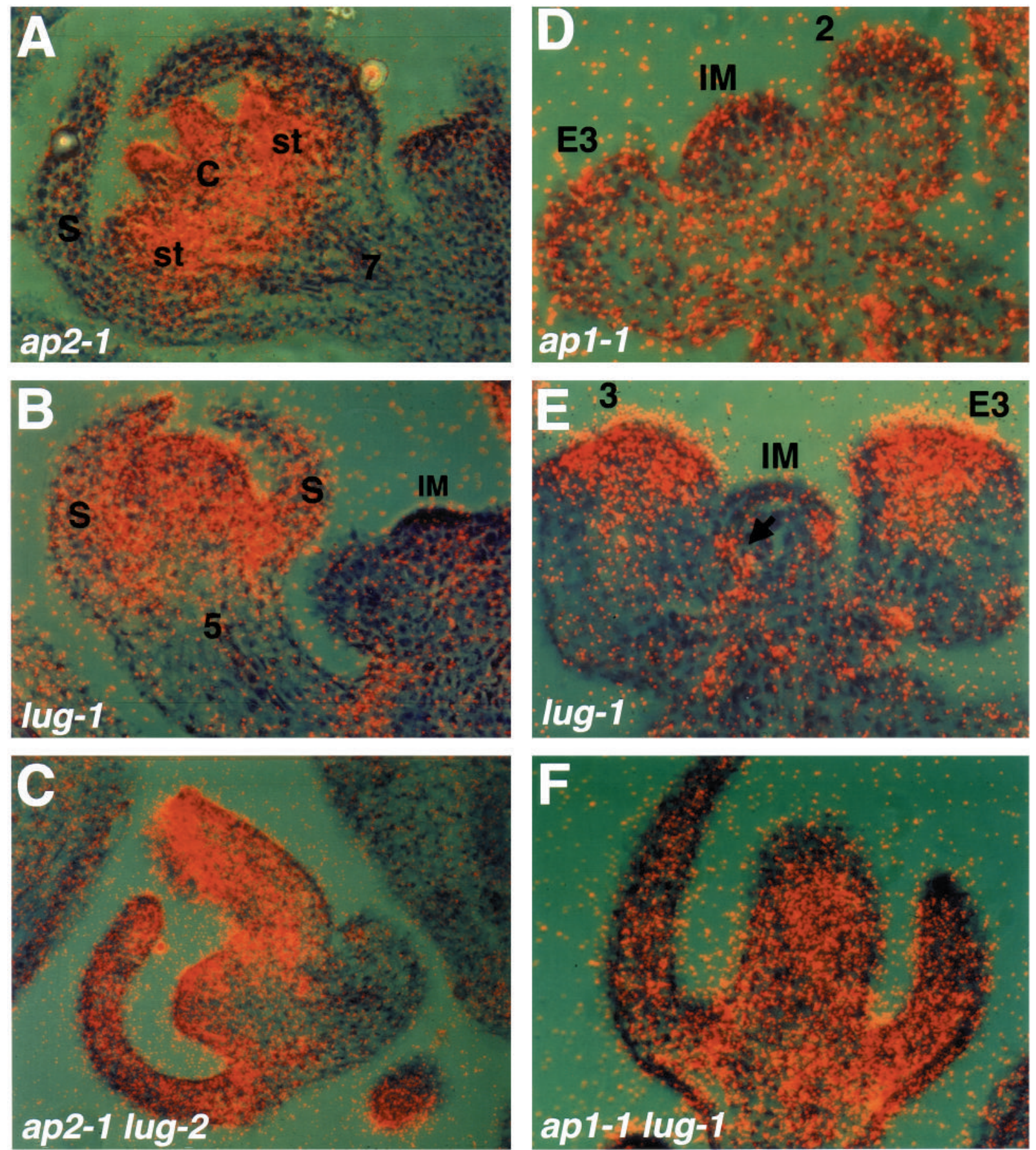

Fig. 3. AGAMOUS $(A G)$ expression in single and double mutants. In situ hybridization of a radioactive $\left({ }^{35} \mathrm{~S}\right)$ AGAMOUS antisense probe to 8 $\mu \mathrm{m}$ longitudinal sections of plant inflorescence apices. The flowers shown are at apical positions 10-20th. The tissues were stained blue with $0.1 \%$ toluidine blue. Photos were taken using bright-field and dark-field double exposures with a red filter during dark exposure. Red grains represent signal. Numbers indicate the stages of corresponding flowers according to Smyth et al. (1990). (A) AG expression in a stage 7 ap2-1 flower. Similarly to wild-type (Drews et al., 1991), $A G$ RNA is detected in developing stamens (st) and carpels (C), but is absent from sepals (s). Petals are still small and not visible in this section. (B) $A G$ expression in a stage 5 lug-1 flower. AG RNA is detected in both sepals (s) and the center dome that will give rise to whorls 2,3 and 4 . (C) $A G$ expression in a stage 7 flower of genotype ap2-1 lug-2.AG RNA is detected in both sepals and in the whorl 4 carpels. Organs in whorls 2 and 3 are severely reduced in number and are absent in this section. (D) $A G$ expression in ap 1-1. Shown are the inflorescence meristem (IM), a late-stage 2 floral primordium (right), and an early stage 3 (E3) floral primordium (left). No $A G$ expression is detected above the background. This AG expression is similar to wild-type and ap2-1 (Drews et al., 1991). (E) Precocious $A G$ expression in $l u g-1$. Shown is an inflorescence meristem (IM), an early stage 3 (E3) floral primordium (right), and a stage 3 floral primordium (left). $A G$ expression is detected in both of the floral primordia, but is absent from the IM. The early stage 3 flower (right) is at a similar developmental stage to the early stage 3 (E3) flower of ap 1-1 shown in D. These two early stage 3 flowers are distinct in the ability to express $A G$. Note the patches of $A G$ RNA in the areas (arrow) of stem and IM. (F) $A G$ expression in a stage 8 flower of genotype ap1-1 lug-1. AG is detected in all the existing whorls. 
stage 3 floral primordia and, by mid stage 3, expands to encompass the region that later gives rise to stamens and carpels. However, in lug (examined alleles: lug-1, lug-3, and lug-4) flowers, $A G$ RNA is detected starting at mid stage 2 (data not shown) and is abundant at early stage 3 (Fig. 3E). The amount of $A G$ RNA detected in early stage 3 lug flowers is greater (Fig. 3E) than that detected in wild-type early stage 3 flowers (Drews et al., 1991). Similar precocious $A G$ expression was also observed in strong ap2-2 mutants (Drews et al., 1991), in ap2-1 lug (ap2-1 lug-1 and ap2-1 lug-2) and ap1-1 lug-1 double mutants (data not shown).

In wild-type, ap2-1, and apl-1 backgrounds, $A G$ RNA expression is restricted to whorls 3 and 4 of stage 3 and older flowers (Fig. 3A; Drews et al., 1991; Gustafson-Brown et al., 1994). However, in lug single (lug-1, lug-3, and lug-4), ap2-1 lug (ap2-1 lug-1 and ap2-1 lug-2) or ap1-1 lug-1 double mutant flowers, $A G$ RNA is detected in all existing whorls (Fig. $3 \mathrm{~B}, \mathrm{C}, \mathrm{F})$. This ectopic $A G$ expression is partial in lug single mutants and is complete in ap2-1 lug or ap 1-1 lug-1 double mutants. In lug-1, 10 out of 17 medial whorl 1 organs express $A G(58 \%)$. However, $A G$ RNA is detected in all medial whorl 1 organs in lug-1 ap2-1 (100\% or 16/16).

\section{The expression of $\mathrm{B}$ class genes $A P 3$ and $P I$}

Both $A P 3$ and $P I$ are ectopically expressed in whorl 1 of $l u g$ mutants. In wild-type, AP3 RNA is detected in primordia of whorl 2 and 3 organs as well as at the base of whorl 1 organs (Jack et al., 1992; Weigel and Meyerowitz, 1993); PI RNA is first detected in regions of floral primordia that give rise to whorls 2, 3 and 4 (stages 3 and 4), and later is confined to the whorls 2 and 3 (Goto and Meyerowitz, 1994). However, both AP3 RNA and PI RNA are detected in whorl 1 organs of lug1 mutants (Fig. 4). In lug-1, the frequency of ectopic PI gene expression is $59 \%$ (30/51 whorl 1 organs), and for AP3 is $50 \%$ (11/22 whorl 1 organs). This is consistent with the incomplete transformation of whorl 1 sepals into staminoid or petaloid sepals.

\section{ag is epistatic to lug with respect to floral organ identity}

If staminoid whorl 2 and staminoid/carpelloid whorl 1 organs in lug flowers result from ectopic $A G$ activity, eliminating $A G$ activity in the lug background would result in normal petals in whorl 2 and normal sepals as well as petaloid sepals in whorl 1 (assuming that occasional ectopic B activity is still present in whorl 1). We constructed lug-1 ag-1 double mutants and observed that the double mutant flowers develop sepals in whorl 1 and petals in whorl 2 with correct organ identity and organ number (Fig. 5C). The similarity of lug-1 ag-1 flowers to $a g-1$ flowers (Fig. 5 compare A and C) suggests that $a g$ is epistatic to lug with respect to floral organ identity. This property of $L U G$ is in sharp contrast to $A P 2$, because ap2-1 ag1 double mutants do not have normal sepals and petals (Fig. 5B; Bowman et al., 1991).

Flowers of lug-1 ag- 1 still exhibit narrow leaves, sepals and petals (Fig. 5C), indicating an $A G$-independent role of $L U G$ in controlling organ shape.

Whorl 1 organs of lug-1 ag- 1 flowers lack petaloid sepals (Fig. 5C). In lug-1, staminoid sepals occur at a frequency of $71 \%$ (10-20th flowers). These staminoid sepals would become petaloid sepals upon the removal of ectopic $A G$ in $l u g-1$ ag- 1 .
However, only subtle petaloid margins were occasionally (16\%) observed in whorl 1 organs (10-20th flowers) of the double mutants. Thus the ectopic B activity is reduced in the absence of ectopic $A G$ activity.

\section{lug enhances the defects of class A mutants, ap2 and ap1 \\ ap2}

ap2-1 lug-1 double mutants exhibit more severe homeotic transformation in flowers than either single mutant. ap2-1, a weak ap 2 allele, develops leaves in whorl 1, staminoid petals in whorl 2 (reduced in number), and largely normal stamens and carpels in whorls 3 and 4 (Figs 1C, 6A). In contrast, ap21 lug- 1 double mutants develop filaments in lateral positions and carpels in medial positions in whorl 1; whorl 2 organs are completely absent, between 0 to 3 stamens are made in whorl 3 ; and whorl 4 carpels are unfused (Figs 1E, 6B). This is consistent with our earlier observation that lug-1 ap2-1 double mutants misexpress $A G$ at a higher frequency than either single mutant (see earlier section). Furthermore, we frequently observed two lateral filaments arising below the two lateral sepals on the pedicels of the double mutants (Fig. 6C). These lateral filaments were rarely observed in $l u g$ and ap2 single mutants. Carpels in lug-1 ap2-1 flowers are not fused and the plants are completely female-sterile. However, lug ap2 double mutants do not exhibit an enhanced phenotype in floral organ shape and leaf shape.

Dominant interactions were observed between strong ap2 and $l u g$, though either mutation alone is recessive. lug- 1 plants heterozygous for ap2-9 exhibit a floral phenotype more severe than lug-1 (Fig. 7A,B, Materials and Methods). lug-1/lug-1 ap2-9/+ flowers have carpelloid sepals in whorl 1 and have lost most or all of the whorl 2 petals, as in lug-1 ap2-1 double mutants. However, lug mutations appear recessive in an ap29/ap2-9 background. The dominant interaction between lug$1 /$ lug- 1 and ap2-9/+ suggests that the products of $A P 2$ and $L U G$ may interact by direct contact, or by defining the same activity at a threshold level (see Discussion).

lug-1 ap2-9 homozygous flowers exhibit stronger defects than the strongest ap2-2 single mutants (compare Figs 6E, 7D with 1D and refer to Bowman et al., 1991). Each floral primordium of lug-1 ap2-9 double mutants is subtended by a bract-like organ at the abaxial position (Fig. 6F). A "bract" usually refers to a small leaf subtending flowers (Gifford and Foster, 1988) and is usually absent in Arabidopsis. However, bract-like organs are observed in several Arabidopsis mutants including lfy (Weigel et al., 1992; Huala and Sussex, 1992) and apl (Irish and Sussex, 1990; Bowman et al., 1993). The floral primordium of lug-1 ap2-9 develops into a single central gynoecium with or without two filamentous whorl 1 organs (Figs 6E, 7D). This stronger defect of lug-1 ap2-9 double homozygotes suggests that $L U G$ and $A P 2$ have overlapping but not completely redundant functions.

\section{ap1}

In ap 1-1 mutant flowers, whorl 1 sepals are transformed into leaves or bracts with axillary flowers developing in their axils. Whorl 2 organs are either absent or are staminoid petals, staminoid, or leaf-like. The whorl 3 and 4 organs are similar to wild type (Fig. 6G; Irish and Sussex, 1990; Bowman et al., 
1993). Thus $A P l$ is required for sepal and petal identity and is a class A gene. lug-1 ap1-1 mutants are similar to lug-1 ap21 double mutants or strong ap 2 single mutants (Fig. 6 compare $\mathrm{H}$ with $\mathrm{B}$, and I with $\mathrm{C}$ ). Medial whorl 1 organs are converted to carpels; lateral whorl 1 organs are filamentous or aborted. Axillary flowers are absent as are floral organs in whorls 2 and 3 . This enhanced phenotype in lug-1 apl-1 double mutants is consistent with our observation that lug-1 apl-1 flowers exhibit enhanced ectopic $A G$ expression (see earlier section), which may suppress axillary flowers. Similarly to lug-1 ap2-1 double mutants, lug-1 ap 1-1 double mutant plants do not exhibit an enhanced phenotype in vegetative tissues.

It has been shown that $A P 1$ RNA accumulation is negatively regulated by $A G$. (Gustafson-Brown et al., 1994). We tested whether ectopic $A G$ activity in whorls 1 and 2 of $l u g$ or $l u g$ ap2-1 mutants could repress $A P 1$ RNA accumulation, by the use of in situ hybridization. In wild-type or ap2-1 (Fig. 8A; Gustafson-Brown et al., 1994), APl RNA is first expressed in the entire floral primordium; by stage $3, A P 1$ RNA is restricted to whorls 1 and 2 as a result of $A G$ expression in the center of the flower. APl RNA is also normally expressed in pedicels of flowers. In lug mutants (lug-1, lug-3, lug-4), AP1 RNA is frequently detected in only one of the two whorl 1 organs in longitudinal sections (Fig. 8B). In lug-1 single mutants, 50\% (22/43) of whorl 1 organs fail to express APl. This defect is more severe in an ap2-1 lug-1 double mutant (Fig. 8C), in which $87 \%$ (26/30) of the whorl 1 organs fail to express AP1. Nonetheless, APl RNA is still detected in pedicels of lug and ap 2-1 lug-1 flowers (Fig. 8C). In ag-1 lug- 1 flowers, API RNA is detected in all whorls (Fig. 8D), suggesting that the ectopic $A G$ expression in lug is responsible for the absence of $A P I$ RNA accumulation.

\section{lug and B class double mutants have additive phenotypes}

The strong ap3 mutation, ap3-3, converts whorl 2 organs into sepals, and whorl 3 organs into carpels, which usually fuse with the central gynoecium (Fig. 7F; Jack et al., 1992). In addition, ap3-3 mutations can result in loss of some organs in whorl 3 (Bowman et al., 1989; Jack et al., 1992). In lug-3 ap33 , whorls 3 and 4 are similar to those of ap3-3 in terms of organ identity, but possess a severely reduced number of whorl 3 carpels; whorl 2 organs are absent and whorl 1 consists of medial carpelloid sepals; lateral sepals are absent or filamentous (Fig. 7G). Evidently, the staminoid sepals found in lug-3 flowers (Fig. 7E) are equivalent to the carpelloid sepals in the lug-3 ap3-3 double mutants (Fig. 7G), indicating persistent presence of ectopic $A G$ activity in the absence of ectopic B activity. Again, carpels of lug-3 ap3-3 mutants exhibit a narrow organ shape and horn-like protrusion (Fig. 7G). Similar results were obtained with $l u g-1$ pi- 1 double mutants (data not shown).

Since the simultaneous presence of ectopic $A P 3$ and $P I$ is required for ectopic $\mathrm{B}$ activity, we crossed a $35 S-A P 3$ transgene into lug- 1 to test whether lug- 1 causes ectopic $P I$ activity. When introduced into wild-type plants, the transgene $35 \mathrm{~S}-A P 3$ ectopically directs expression of AP3 RNA in all four whorls, thereby transforming carpels into stamens in whorl 4. Whorl 1 organs, however, remain sepals due to the absence of PI expression (Fig. 6J; Jack et al., 1994). lug-1/lug-1 35S-
$A P 3 /+$ flowers exhibit additive effects in whorls 2, 3 and 4: petals or staminoid petals in whorl 2 , stamens in whorls 3 and 4. However, the medial whorl 1 organs are completely transformed into stamens (Fig. 6K,L), while the lateral organs remain sepals. Thus, lug results in ectopic PI activity in the medial whorl 1 organs, and the transgene enhances the homeotic transformation of these organs by providing abundant $A P 3$ activity.

\section{sup and lug mutations are additive}

sup mutant flowers develop extra stamens at the expense of the central gynoecium (Bowman et al., 1992; Schultz et al., 1992). Thus SUP is required to prevent B activity in whorl 4. lug-1 sup-4 double mutants exhibit additive effects (Fig. 7H,I). Whorls 3 and 4 are sup- 4 like: stamens are formed at the expense of carpel tissues; the outer two whorls are lug- 1 like: carpelloid sepals and reduced number of petals. The number of stamens is reduced in the double mutant compared to sup4 alone.

\section{Early termination of inflorescences in Ify lug double mutants}

The strong lfy mutation, lfy- 6 , causes partial conversion of floral meristems to shoot meristems, and $l f y-6$ inflorescences terminate with bracts, carpelloid bracts or a carpelloid mass (Weigel et al., 1992). lug mutations facilitate the termination of inflorescence shoots in lfy-6. lug-3 lfy-6 inflorescences give rise to 3-4 cauline leaves (slightly fewer than lfy-6 alone) with secondary shoots in their axils, and then 3-4 flowers with subtending bracts. Soon afterward, the inflorescence terminates with bracts or carpelloid bracts (Fig. 7L). This is in contrast to both lug-3 and lfy-6 single mutant inflorescences, which produce at least 25-30 flowers before termination (Fig. 7J,K). Double mutants between a weak lfy allele, lfy-5, and lug-l exhibit similar early termination (Fig. 6O). This phenotype is similar to the early termination observed in lfy tfl double mutants (Shannon and Meeks-Wagner, 1993; Schultz and Haughn, 1993).

In addition, lug-1 appears to enhance the floral phenotype of the weak lfy-5 mutants (Fig. 6 compare $M$ with N). lfy-5 and lfy- 6 single mutants have flowers of very different phenotypes (Figs 6M, 7K; Weigel et al., 1992); lug-1 enhances the floral phenotype of $l f y-5$, and lfy-5 lug- 1 double mutant flowers are similar to those of lfy- 6 . Nevertheless, lfy lug double mutants have narrow leaves and floral organs (Figs 6N,O, 7L).

\section{DISCUSSION}

\section{LUG is a class A cadastral gene}

This study indicates that $L U G$ is a negative regulator of $A G$ (Fig. 9A). Both the organ identity transformation and the organ number reduction in lug mutants are mediated through ectopic $A G$ expression. Unlike $A P 2, L U G$ is not required to specify sepal or petal identity, shown by the fact that lug-1 ag- 1 double mutants develop normal sepals and petals (narrow in shape). Thus, $L U G$ is a cadastral gene whose main role in the determination of floral organ identity is to negatively regulate $A G$.

Class A function in whorls 1 and 2 can be divided into two 

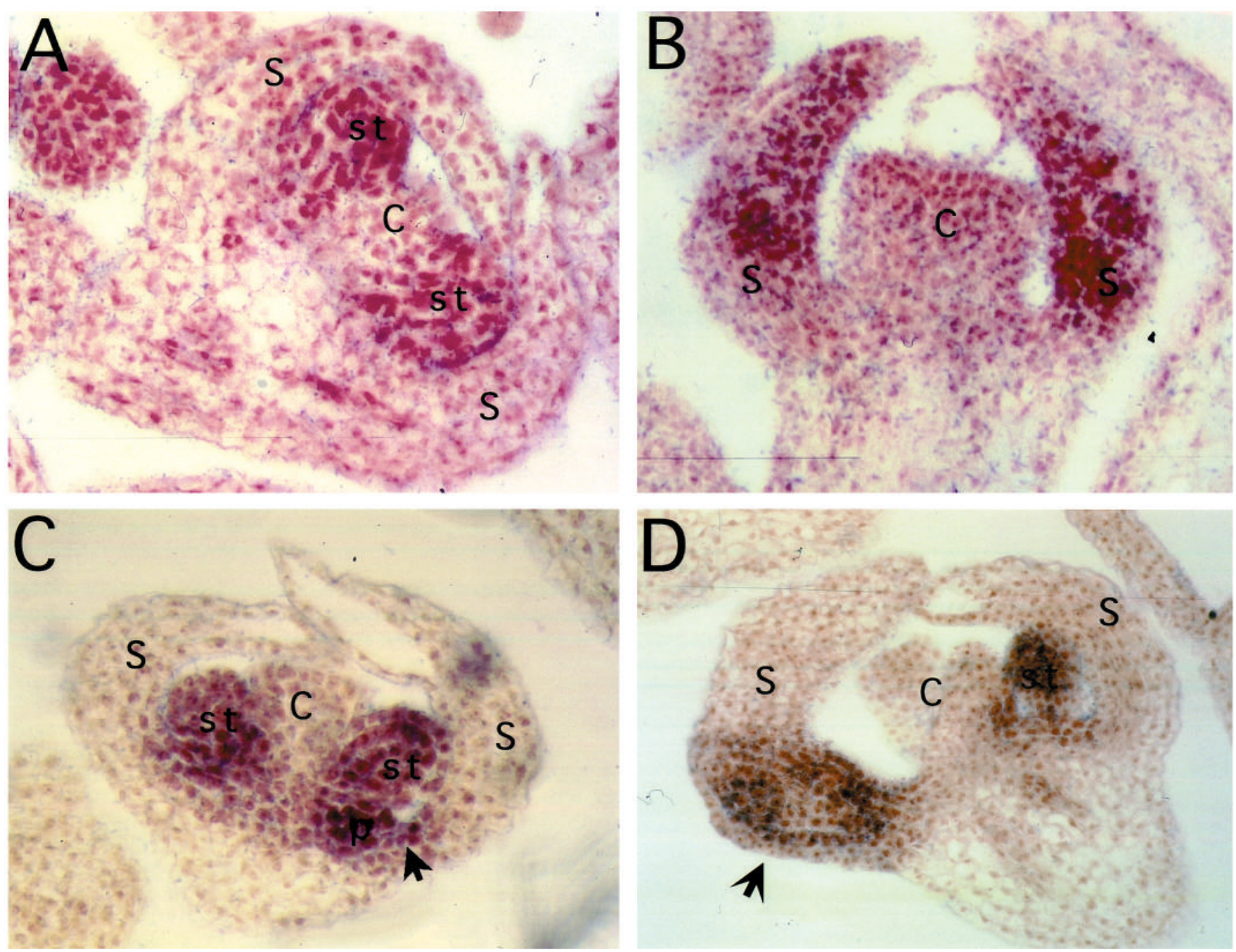

Fig. 4. Class B gene expression in wild-type and $l u g-1$ mutants. In situ hybridization of Dig (digoxigenin) labeled antisense probes of $P I$ (A, B) or $A P 3(\mathrm{C}, \mathrm{D})$ to $8 \mu \mathrm{m}$ longitudinal sections of young wild-type and lug inflorescence apices (Materials and Methods). The images are brightfield microphotographs. (A) In this wild-type stage 6 flower, PI RNA is absent from sepal (s) and carpel (C) primordia but is detected in the stamen (st) and petal primordia (petal is small and absent from this section). (B) PI RNA is detected in both sepals of this stage 7 lug- 1 flower. The stamen and petal primordia are severely reduced in number, and thus missing from this section. (C) In this wild-type stage 7 flower, $A P 3$ RNA is absent in sepal (S) and carpel (C) primordia but is detected in the stamen (st) and petal (P) primordia. AP3 RNA is also detected at the base of the sepal (arrow). (D) AP3 RNA is detected in one of the sepals (arrow) in this stage 7 flower of lug-1.

subfunctions: specification of sepal and petal identity and repression of $A G$ expression. The three class A genes $L U G$, $A P 2$, and $A P 1$ are distinct from one another with respect to these two subfunctions (Fig. 9B). APl is required for organ identity specification but not for $A G$ repression (Mandel et al., 1992; Gustafson-Brown et al., 1994). $L U G$ is required for $A G$ repression but not for the organ identity specification (this study). $A P 2$ is required for both organ identity specification and $A G$ repression (Bowman et al., 1991).

However, our study also suggests that $A P 1$ is likely a redundant repressor of $A G$. apl-1 enhances floral homeotic transformation as well as $A G$ misexpression in lug-1 ap 1-1 double mutants, indicating a role for $A P l$ in $A G$ repression in the absence of $L U G$. Similarly, in the absence of $A P 2, A P 1$ contributes to $A G$ repression as indicated by the enhanced homeotic transformation in outer whorl organs of ap1-1 ap21 double mutants (Bowman et al., 1993). This is consistent with the observation that $A G$ is occasionally expressed in whorl 1 organs of apl mutants (Weigel and Meyerowitz, 1993), and that carpelloid whorl 1 and staminoid whorl 2 organs are sometimes observed in apl mutants (Bowman et al., 1993; Schultz and Haughn, 1993).

The weak ap2 allele, ap2-1, is defective in sepal and petal specification (Bowman et al., 1991) but retains, at least partially, the subfunction for $A G$ repression, because $A G$ RNA distribution is still restricted to whorls 3 and 4 of the ap2-1 flowers (Fig. 3A; Drews et al., 1991). The lug- 1 single mutation causes only $58 \%$ of whorl 1 organs to misexpress $A G$ (this study). However, ap2-1 lug-1 flowers exhibit enhanced floral homeotic transformation as well as $100 \% A G$ misex- 

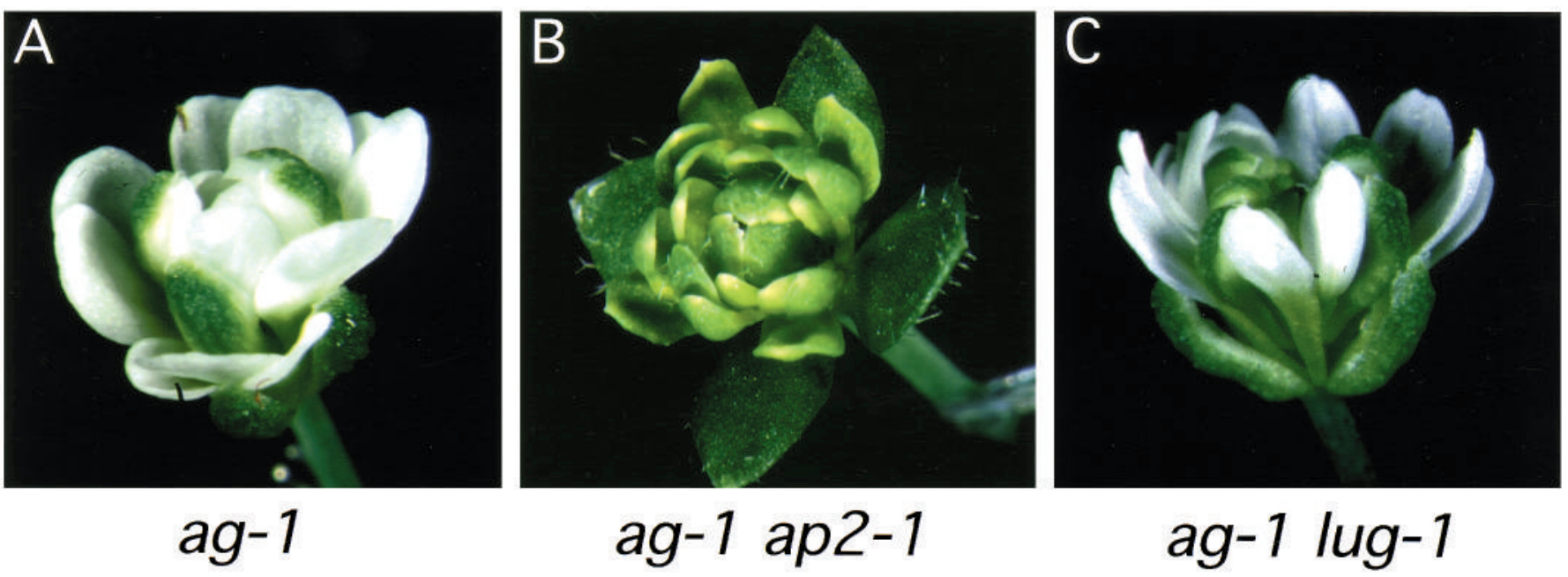

Fig. 5. The ag- 1 lug- 1 flower is similar to ag- 1 but is distinct from ag- 1 ap2-1 flowers. (A) An ag- 1 flower. Whorls 1 and 2 are similar to wildtype consisting of 4 sepals and 4 petals respectively. Whorl 3 consists of six petals, and whorl 4 consists of a new flower. (B) An $a g-1$ ap2-1 flower. Whorl 1 consists of 4 leaves; whorls 2 and 3 give rise to 4 and 6 organs intermediate between petals and stamens (Bowman et al., 1991); whorl 4 is another flower of the same phenotype. (C) An ag-1 lug-1 flower. Similarly to ag- 1 (see A), whorl 1 and 2 are 4 sepals and 4 petals respectively. Whorl 3 consists of 6 petals, and whorl 4 is another flower. The sepals and petals are narrow in shape.

pression in whorl 1, indicating that ap2-1 and lug-1 each enhances the other's defect in $A G$ repression. This synergy between ap 2 and lug is also made evident by the dominant interaction between lug-1/lug-1 and ap2-9/+, and could be explained by two alternative mechanisms: (1) a threshold level of an activity composed of $L U G$ and $A P 2$ may be required for $A G$ repression, lug-1/lug-1 ap2-9/+ plants possess a level of activity much lower that of lug/lug $+/+$, and this difference in the activity level is manifested in their differences in phenotypes; or (2) $A P 2$ and $L U G$ proteins may form heteromultimeric complexes for $A G$ repression. A copy of the mutant ap 2 protein may dramatically affect the activity of the complex as in the case of dominant negative types of interactions (Herskowitz, 1987).

Since the phenotype of double mutant lug-1 ap2-9 is more severe than the phenotype of the strongest reported ap 2 allele, ap2-2, $L U G$ and $A P 2$ are partially redundant in their $\mathrm{A}$ cadastral function. However, $L U G$ appears to play a relatively minor role compared to $A P 2$ with respect to this A cadastral activity. This conclusion is based on two observations: that all lug mutations cause incomplete and less severe homeotic transformation than ap2 mutants, and that lug mutations are recessive in an ap2-9/ap2-9 background.

\section{Other roles of $L U G$}

Under our growth conditions, cauline leaves and late rosette leaves of $l u g$ are narrower and more serrated than wild type. lug floral organs are also narrower and more pointed than in wild-type. This effect of lug on leaf and floral organ shape is independent of the activities of $A G, A P 2, A P 1, P I, A P 3$, sup and $L F Y$; thus $L U G$ may directly or indirectly regulate genes specifying organ shape.

$L U G$ is essential for proper carpel fusion and septum formation. The horn-like protrusion at the tips of carpels may prevent the fusion of carpels by continuous outgrowth. These horn-like protrusions are also found in lug mutants whorl 1 carpelloid organs in lug, and have never been observed in wildtype. This horn-like protrusion in lug is found in all double mutants examined, including those of lug with ap2, ap $1, p i$, $a p 3$, and lfy. It is possible that this defect of lug is associated with the similar defects in the shape of leaf and floral organs.

The diverse defects of lug mutants suggest that $L U G$ may be involved in regulating several different developmental processes, in which $L U G$ may interact with different partners.

\section{Is LUG the predicted cadastral gene?}

Several lines of evidence suggested the existence of factors other than $A P 2$ for $A G$ repression. First, $A P 2$ RNA is expressed in all four whorls of a flower (Jofuku et al., 1994), yet AP2 only represses $A G$ expression in whorls 1 and 2 (Drews et al., 1991). Thus the ability of $A P 2$ to repress $A G$ must depend on additional spatially specific factor(s). Second, when $a g$ mutations cause ectopic $A P 2$ organ identity function in whorls 3 and 4, they do not cause ectopic $A P 2$ cadastral activity because $A G$ mutant RNA is correctly expressed in whorls 3 and 4 (Gustafson-Brown et al., 1994). This again suggests the existence of at least one additional factor, whose activity is spatially-restricted regardless of $A G$ activity, and whose activity is neither required for, nor interferes with, sepal and petal specification, because normal sepals and petals are ectopically formed in whorls 3 and 4 of ag mutants. $L U G$ could be a candidate for such a factor, for it is clearly required for $A G$ repression in whorls 1 and 2 and it is not required for sepal and petal specification.

Nonetheless, the roles of $L U G$ in regulating leaf and floral organ shape as well as its role in regulating stamen number and carpel fusion indicate that $L U G$ is active, at least at some developmental stages, in vegetative parts of plants and in whorls 3 and 4 . Thus, $L U G$ may not be a spatially-restricted whorl 1 and 2 factor. It is likely that $L U G$ is part of the class A cadastral complex just as AP2 may be part of the class A cadastral complex. The molecular cloning of $L U G$, and the consequent 

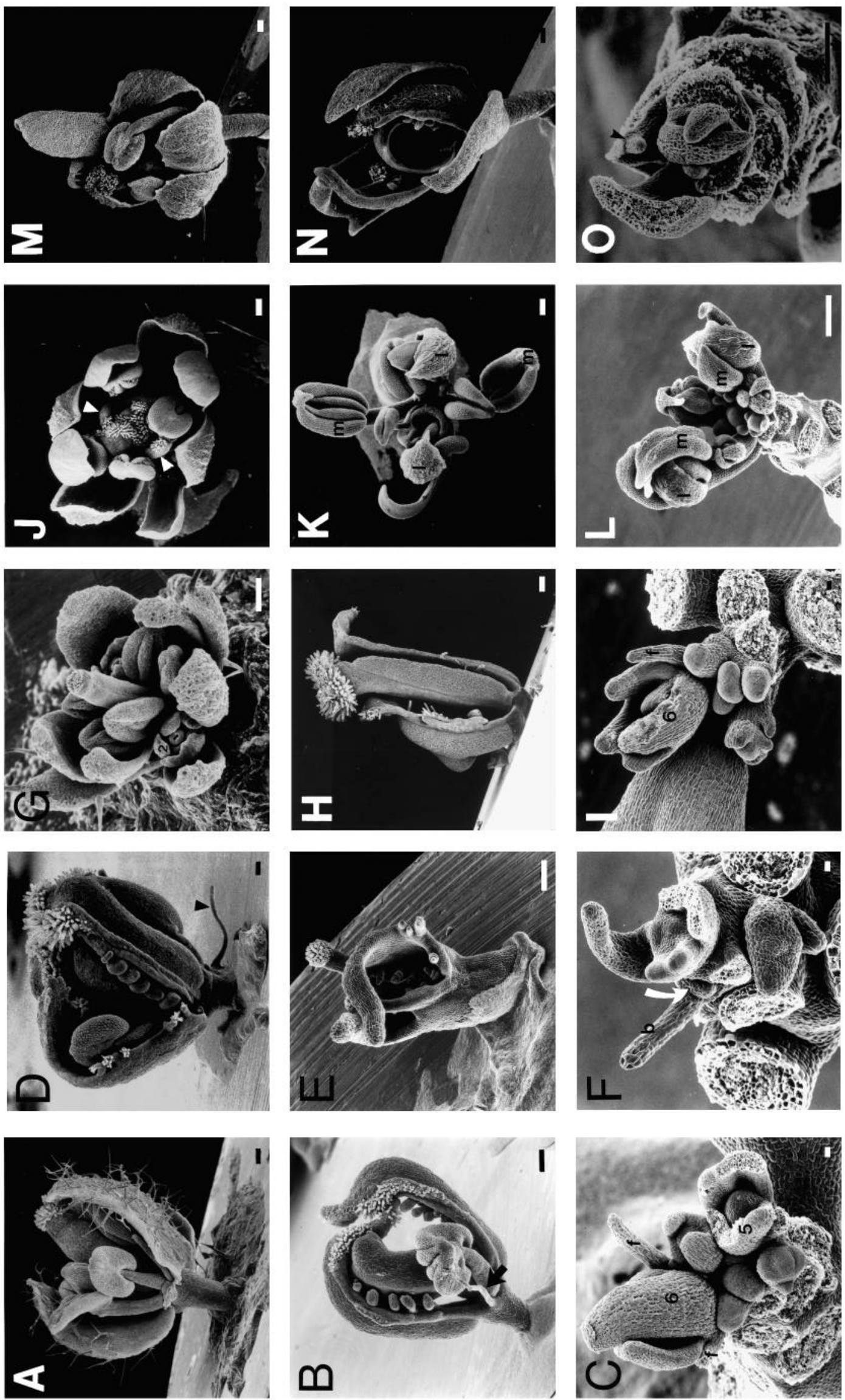
ability to detect and change its region and time of expression should help clarify this issue.

\section{lug indirectly alters the domain of B gene activity}

The ectopic B class activity in lug mutants appears to be an indirect effect through ectopic $A G$ activity because eliminating $A G$ in ag-1 lug-1 double mutants greatly reduces ectopic B activity. One explanation is that both $A P 1$ and $A P 2$ activities are repressed by ectopic $A G$ in whorl 1 organs of lug mutants, and either $A P 1$ or $A P 2$ activity is required to prevent $P I$ or $A P 3$ from being expressed in whorl 1 (Fig. 9A). This is supported by the observation that apl-5, a weak apl mutation, exhibits petaloid sepals at the medial position in whorl 1 (Bowman et al., 1993). Similarly, ap2-8 and ap2-9 exhibit staminoid features in whorl 1 organs at the medial position (Bowman et al., 1991). An alternative explanation is that ectopic $A G$ directly causes ectopic B activity in whorl 1 of lug mutants. For instance, $A G$ may cause medial sepal primordia to arise closer to the region of whorl 2 in a floral primordium, and as a result, the medial whorl 1 organs are more likely to express B activity.

\section{Common and unique properties of lug, ap1 and ap2}

Fig. 6. Scanning electron microscopic (SEM) pictures of single and double mutants. Bars equal $10 \mu \mathrm{m}$ in $\mathrm{C}, \mathrm{F}$, and I; bars equal $100 \mu \mathrm{m}$ in the remaining photos. Numbers indicate the stages of respective flowers. Abbreviations are: $f$, filament; $b$, bract; $m$, medial; 1 , lateral; $2^{\circ}$, secondary flower. (A) An $a p 2-1$ flower at $29^{\circ} \mathrm{C}$. One first whorl leaf is removed to reveal interior organs. (B) A lug-1 ap2-1 flower with two medial whorl 1 carpels and two lateral whorl 1 filaments (arrow). Whorl 2 organs are completely absent, whorl 3 has one stamen, and whorl 4 has an abnormal gynoecium. (C) An inflorescence of a lug-1 ap2-1 double mutant. A basal stage 6 flower (6) is flanked by two lateral filaments (f) (one of which was removed). These filaments are not observed in mature flowers (see B), and thus are aborted later. In the stage 5 flower (5), the fused whorl 1 organs were dissected away to reveal the flat central dome and the absence of whorl 2 organ primordia. (D) An ap2-9 flower with a similar phenotype to lug-1 ap2-1 (see B). (E) A lug-1 ap2-9 flower consisting of one gynoecium. The gynoecium is unfused and has horn-like protrusions. (F) An inflorescence of lug-1 ap2-9. Each floral primordium consists of a bract (b) subtending a flat dome (arrow), which will develop into a single gynoecium. The bract is filament-like and frequently aborts. (G) An ap 1-1 with axillary flowers $\left(2^{\circ}\right)$ developing in the axils of whorl 1 sepals. (H) A lug-1 ap1-1 flower. Similarly to lug-1ap2-1 (see B), the two medial whorl 1 organs are carpelloid, and the two lateral whorl 1 organs are absent or filaments. Whorl 2 and 3 organs do not develop. Axillary flowers are absent. (I) An inflorescence of genotype lug-1 ap 1-1. Similarly to lug-1 ap2-1 (see C), flowers have flanking lateral filaments (f) that abort later. Whorl 1 organs sometimes fuse with one another as shown in the stage 6 flower. Whorls 2 and 3 organs do not develop. (J) A 35S-AP3/+ flower. Whorls 1, 2 and 3 organs are wild-type, and whorl 4 consists of stamens with stigmatic papillae on top (arrows). (K) A basal lug-1/lug-1 35S-AP3/+ flower. The two medial whorl 1 organs (m) are stamens, while the two lateral whorl 1 organs (l) are sepals. The number of organs in whorls 2 and 3 is severely reduced. (L) An inflorescence of lug-1/lug-1 35S-AP3/+ showing the staminoid medial whorl 1 organs (m). (M) A lfy-5 flower. (N) A lfy-5 lug-1 flower. All organs (except the two innermost carpels) consist of sepal/carpel mosaic tissues. The few floral organs arise in a partially spiral pattern. (O) A young lfy-5 lug- 1 inflorescence terminating with bracts and carpelloid bracts (arrow indicates a developing ovule).

\section{mutants}

The combined functions of $L U G, A P 1$ and $A P 2$ contribute to the so-called A function. Mutations in any one of these three genes affect A function to certain degrees and thus exhibit similarities as follows: (1) flowers at more apical positions have more severe phenotypes; (2) the medial whorl 1 organs are more readily transformed into carpelloid and staminoid sepals than lateral whorl 1 organs, which are more likely to develop into sepals, leaves, filaments, or to be absent; (3) all class A mutants have a reduced number of whorl 2 and 3 organs due to the failure of organ initiation. These similarities might be attributed to changes in $A G$ activity: (1) endogenous $A G$ activity may increase apically; (2) medial whorl 1 organs might be more susceptible to ectopic $A G$ or the lateral whorl 1 organs might reside outside the influence of organ identity genes because they initiate at a lower position in a floral meristem (Smyth et al., 1990; Bowman et al., 1991, 1993); (3) the loss of whorl 2 and 3 organs can be attributed, at least in part, to ectopic $A G$ activity, because removing $A G$ activity in any of the A class mutants can recover some or most of the lost organs (Irish and Sussex, 1990; Bowman et al., 1991, 1993; Weigel and Meyerowitz, 1993).

lug, apl and ap2 mutants also exhibit unique properties. For instance, lug affects leaf and floral organ shape and septum fusion, apl causes axillary flowers in the axils of whorl 1 bracts, and enhances defects of lfy in floral meristem identity specification (Irish and Sussex, 1990; Weigel et al., 1992; Bowman et al., 1993), and ap2 causes abnormal seed coats (Leon-Kloosterziel et al., 1994; Jofuku et al., 1994). These differences make it unlikely that one class A gene is strictly an upstream regulator of another class A gene. It is possible, however, that one gene regulates the expression of another gene at a specific time or in specific tissues as is the case where $A P 1$ RNA expression in a stage 2 and later floral primordium is regulated indirectly by $L U G$ (this study).

\section{Flower development in other plant species}

Studies on flower development in snapdragon, petunia, tobacco, and tomato indicated that despite variations in floral form and size, the essential mechanisms underlying the development of floral ground plan are similar (Coen and Meyerowitz, 1991; Weigel and Meyerowitz, 1994). Floral homeotic genes or floral homeotic mutants with $\mathrm{A}, \mathrm{B}$, and $\mathrm{C}$ functions are found in several plant species studied (Carpenter and Coen, 1990; Schwarz-Sommer et al., 1990; Sommer et al., 1992; Angenent et al., 1993; van der Krol et al., 1993; Pnueli et al., 1994). Similarly to lug and ap2 in Arabidopsis, the blind (bl) mutation in Petunia hybrida causes ectopic expression of pMADS3, a homologue of $A G$ and PLE, in all floral whorls and in leaves (Tsuchimoto et al., 1993). However, $b l$ mutants only exhibit homeotic conversions of corolla limb to antheroid structures (de Vlaming et al., 1984; Angenent et al., 1993; Tsuchimoto et al., 1993). ovulata (ovu) in Antirrhinum majus (snapdragon) is a dominant gain-of-function mutation, found to be due to a transposon insertion within PLENA (PLE), the snapdragon class $\mathrm{C}$ gene. This insertion also causes ectopic expression of $P L E$ and thus ectopic $\mathrm{C}$ function in whorls 1 and 2 (Bradley et al., 1993). Understanding how domain-specific activities of floral homeotic genes are regulated in Arabidopsis and other plant species will shed light on the evolution of one key control mechanism in floral pattern formation. 

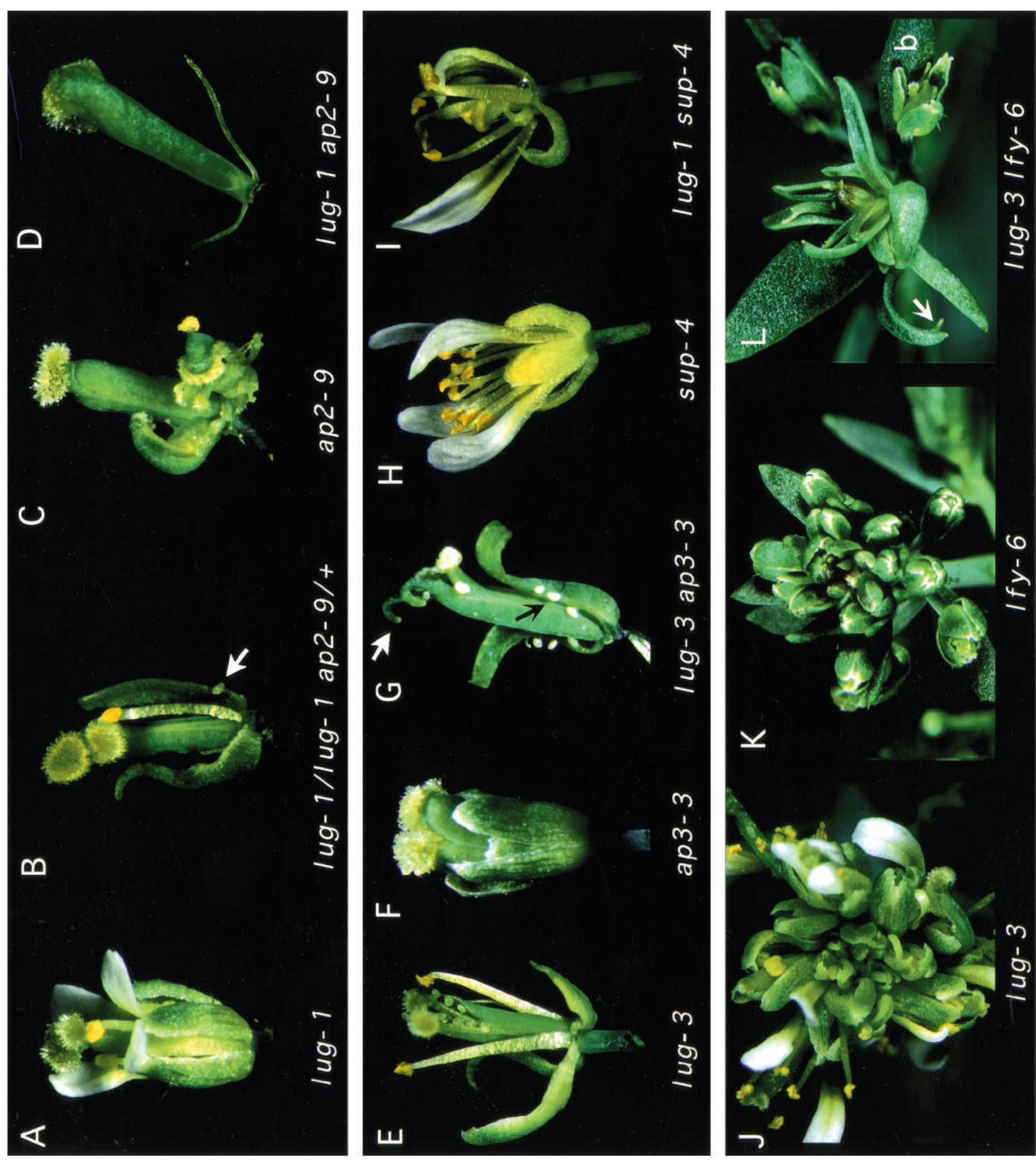

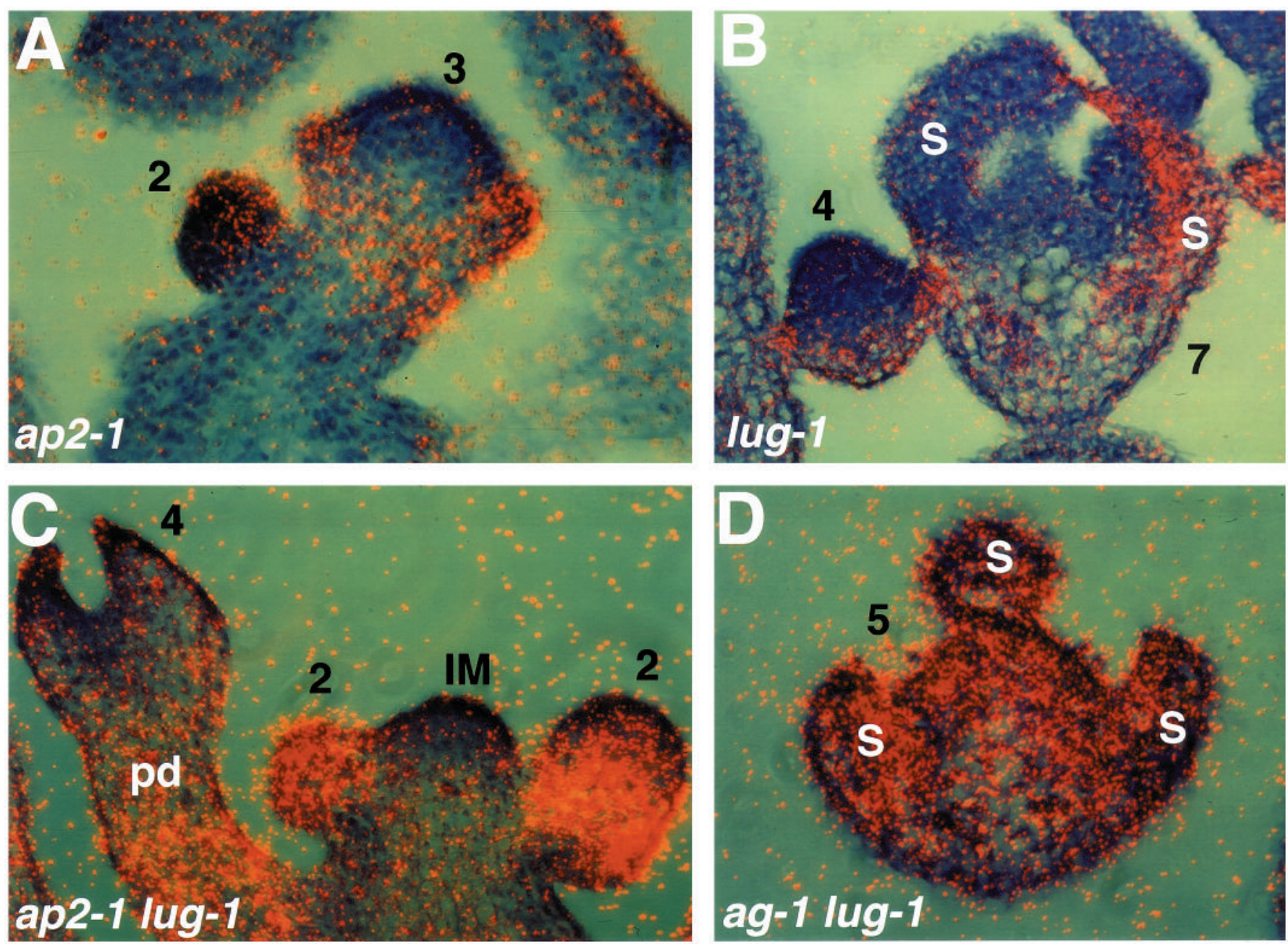

Fig. 8. $A P 1$ expression in single and double mutants. In situ hybridization of a radioactive $\left(\mathrm{S}^{35}\right) A P 1$ antisense probe to $8 \mu \mathrm{m}$ longitudinal sections of plant inflorescence apices. The flowers shown are at apical positions 10-20th. The tissue staining and photography are described in Fig. 3 legend. The number indicates the stages of corresponding flowers according to Smyth et al. (1990). Abbreviations are: IM, inflorescence meristem; pd, pedicel. (A) AP1 expression in ap2-1. Similarly to wild-type (Gustafson-Brown et al., 1994), AP1 RNA is detected early in the entire floral primordium as shown in the stage 2 flower. At stage 3, API RNA is detected in the region where whorl 1 and 2 organs will develop. (B) AP1 expression in a stage 4 (left) and a stage 7 (right) lug-1 flower. AP1 RNA is detected in only one of the two sepals (s) of the stage 7 flower. (C) APl expression in flowers of genotype ap2-1 lug-1. Shown is an inflorescence meristem (IM) flanked by an early stage 2 (left ), a late stage 2 (right), and a stage 4 flower. At the beginning, APl expression is identical to that of wild-type as shown in the early stage 2 flower (left to the IM). In the late stage 2 (right) and the stage 4 flowers, API RNA is not present in floral meristems but remains in the pedicels (pd). (D) APl expression in a stage 5 flower of genotype ag-1 lug-1. APl RNA is detected in all sepals (s) (due to the angled section, three sepals are shown here). API RNA is also detected in the central dome that will give rise to whorls 2,3 and 4.

Fig. 7. Double mutant combinations between lug and ap2, ap3, sup, and lfy. The top panel illustrates a increase in the severity of phenotype by losing one or more copies of wild-type $A P 2$ and $L U G$. (A) A basal lug-1 flower (second flower) with little if any homeotic transformation. (B) A basal lug-1/lug-1 ap2-9/+ flower (second flower). Medial whorl 1 sepals have ovules (arrow) developing along the margin. The whorl 2 organs are absent and whorl 3 stamens are reduced in number. (C) An ap2-9 flower. The medial whorl 1 carpels exhibit both stigmatic papillae and ovules along the margins. Lateral whorl 1 organs are filaments or absent. Whorl 2 and 3 organs are not formed. (D) A lug-1ap2-9 double homozygous flower. Almost all organs in whorls 1,2 and 3 are absent. Occasionally, filaments are observed in whorl 1 . The middle panel shows double mutants between lug and ap3 or sup. (E) An apical lug-3 flower. (F) An apical ap3-3 flower. (G) An apical lug-3 ap3-3 flower. In whorl 1 , lateral organs are absent (as shown) or are filaments, medial organs are carpelloid with ovules developing along the margins (black arrow). Whorl 2 organs are absent, and the central gynoecium consists of roughly three carpels, one of which is probably a whorl 3 carpel. Note the horn-like (white arrow) protrusions associated with the carpels. (H) A sup-4 flower. Whorls 3 and 4 consist of 12 stamens. (I) A lug-1 sup-4 flower. Carpelloid sepals and slightly staminoid petals are made in whorls 1 and 2 respectively. Whorl 3 has reduced number of stamens; whorl 4 consists of stamens and staminoid carpels. Some sepals were removed to reveal the interior. The bottom panel illustrates inflorescences of lug-3, lfy- 6 and lug-3 lfy- 6 at comparable developmental stages. (J) A young lug-3 inflorescence. At least 13 flowers are visible. (K) A young lfy-6 inflorescence. At least 18 flowers are visible. (L) A young lug-3 lfy-6 inflorescence. Only two flowers are visible. The inflorescence terminates early with bracts (b) or carpelloid bracts (arrow indicates carpelloid tissue). Note the narrow shape of leaves and bracts. 
A.

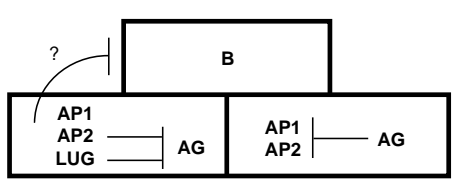

B.

$\begin{array}{lcc}\text { Class A genes } & \text { Repress } A G & \text { Specify sepal and petal identity } \\ \begin{array}{c}A P 1 \\ L U G\end{array} & - & + \\ A P 2 & + & - \\ & + & +\end{array}$

Fig. 9. The role of $L U G$ in floral organ identity determination. (A) The role of $L U G$ in the $\mathrm{ABC}$ model. $L U G$ is proposed to act together with $A P 2$ in whorls 1 and 2 for $A G$ repression. $A P 1$ and $A P 2$ may negatively regulate $\mathrm{B}$ activity in whorl 1 (see Discussion on "LUG alters the domain of B gene activity"). (B) The class A genes can have two subfunctions: specifying sepal and petal identity and repressing $A G$. APl only has the function for specifying sepal and petal identity, $L U G$ only has a function for $A G$ repression, and $A P 2$ possesses both functions for sepal and petals identity specification and for $A G$ repression. "+" indicates a requirement for the respective gene and "-" indicates a non-essential role for the respective gene.

We thank Susan Apostolaki for help with the genetic screen and David Smyth for initially pointing out the resemblance of our enhancer mutants to leunig and Fl-89. We thank George Fox, Tom Jack, Steven Jacobsen, Joshua Levin, Kiyotaka Okada, David Smyth, and Detlef Weigel for giving us lug alleles. We also thank John Bowman, Caren Chang, Steven E. Clark, Justin Goodrich, Tom Jack, Steve Jacobsen, Beth Krizek, Joshua Levin, Jose Luis Riechmann, Mark Running, Hajime Sakai, Leslie Sieburth, David Smyth, Detlef Weigel, and Liz Zimmer for discussion, suggestions and comments on the manuscript. Z. L. is a DOE-energy Biosciences Research Fellow of the Life Science Research Foundation, and also previously a Damon Runyon-Walter Winchell Cancer Research Fund postdoctoral fellow. This work was supported by NIH grant GM 45697 to E. M. M.

\section{REFERENCES}

Akam, M. E. (1987). The molecular basis for metameric pattern in the Drosophila embryo. Development 101, 1-22.

Angenent, G. C., Franken, J., Busscher, M., Colombo, L. and van Tunen, A. J. (1993). Petal and stamen formation in petunia is regulated by the homeotic gene FBP1. Plant J. 4, 101-112

Bowman, J. L., Smyth, D.R. and Meyerowitz, E.M. (1989). Genes directing flower development in Arabidopsis. Plant Cell 1, 37-52.

Bowman, J. L., Smyth, D. R. and Meyerowitz, E. M. (1991). Genetic interactions among floral homeotic genes of Arabidopsis. Development 112, $1-20$.

Bowman, J. L., Sakai, H., Jack, T., Weigel, D., Mayer, U. and Meyerowitz, E. M. (1992). SUPERMAN, a regulator of floral homeotic genes in Arabidopsis. Development 114, 599-615.

Bowman , J. L., Alvarez, J., Weigel, D., Meyerowitz, E. M. and Smyth, D. R. (1993). Control of flower development in Arabidopsis thaliana by APETALA1 and interacting genes. Development 119, 721-743.

Bradley, D., Carpenter, R., Sommer, H., Hartley, N. and Coen, E. (1993). Complementary floral homeotic phenotypes result from opposite orientation of a transposon at the plena locus of Antirrhinum. Cell 72, 85-95.
Carpenter, R. and Coen, E.S. (1990). Floral homeotic mutations produced by transposon-mutagenesis in Antirrhinum majus. Genes Dev. 4, 1483-1493.

Coen, E. S. and Meyerowitz, E. M. (1991). The war of whorls: genetic interactions controlling flower development. Nature 353, 31-37.

de Vlaming, P., Gerats, A. G. M., Wiering, H. and Wijsma, H. J. W. (1984). Petunia hybrida: a short description of the action of 91 genes, their origin and map location. Plant Mol. Biol. Rep. 2 (2), 21-43.

Drews, G. N., Bowman, J. L. and Meyerowitz, E. M. (1991). Negative regulation of the Arabidopsis homeotic gene AGAMOUS by the APETALA2 product. Cell 65, 991-1002.

Gifford, E. M. and Foster, A. S. (1988). Morphology and Evolution of Vascular Plants, 3rd edition. New York: Freeman.

Gustafson-Brown, C., Savidge, B. and Yanofsky, M. F. (1994). Regulation of the Arabidopsis floral homeotic gene APETALA1. Cell 6, 131-143.

Goto, K. and Meyerowitz, E. M. (1994). Function and regulation of the Arabidopsis floral homeotic gene PISTILLATA. Genes Dev. 8, 1548-1560.

Herskowitz, I. (1987). Functional inactivation of genes by dominant negative mutations. Nature 329, 219-222.

Huala, E. and Sussex, I.M. (1992). $L E A F Y$ interacts with floral homeotic genes to regulate Arabidopsis floral development. Plant Cell 4, 901-913.

Ingham, P. (1988). The molecular genetics of embryonic pattern formation in Drosophila. Nature 335, 25-34.

Irish, V.F. and Sussex, I.M. (1990). Function of the apetala-1 gene during Arabidopsis floral development. Plant Cell 2, 741-753.

Jack, T., Brockman., L. L. and Meyerowitz, E. M. (1992). The homeotic gene APETALA3 of Arabidopsis thaliana encodes a MADS box and is expressed in petals and stamens. Cell 68, 683-697.

Jack, T., Fox, G. L. and Meyerowitz, E. M. (1994). Arabidopsis homeotic gene APETALA3 ectopic expression: transcriptional and post-transcriptional regulation determine floral organ identity. Cell 76, 703-716.

Jofuku, D., den Boer, B., Van Montagu, M. and Okamuro, J. (1994). Control of Arabidopsis flower and seed development by the homeotic gene APETALA2. Plant Cell 6, 1211-1225.

Komaki, M. K., Okada, K., Nishino, E. and Shimura, Y. (1988). Isolation and characterization of novel mutants of Arabidopsis thaliana defective in flower development. Development 104, 195-203.

Kunst, L., Klenz, J. E., Martinez-Zapater, J. and Haughn, G. W. (1989). AP2 gene determines the identity of perianth organs in flowers of Arabidopsis thaliana. Plant Cell 1, 1195-1208.

Langdale, J. A., Metzler, M. C. and Nelson, T. (1987). The argentia mutation delays normal development of photosynthetic cell-types in Zea mays. Dev. Biol. 122, 243-255.

Leon-Kloosterziel, K. M., Keijzer, C. J. and Koornneef, M. (1994). A seed shape mutant of Arabidopsis that is affected in integument development. Plant Cell 6, 385-392.

Lewis, E. B. (1978). A gene complex controlling segmentation in Drosophila. Nature 276, 565-570.

Mandel, M.A., Gustafson-Brown, C., Savidge, B. and Yanofsky, M.F. (1992). Molecular characterization of the Arabidopsis floral homeotic gene APETALA1. Nature 360, 273-277.

Norman, C., Runswick, M., Pollock, R. and Treisman, R. (1988). Isolation and properties of cDNA clones encoding SRF, a transcription factor that binds to the $c$-fos serum response element. Cell 55, 989-1003.

Passmore, S., Maine, G.T., Elble, R., Christ, C. and Tye, B. K. (1988). A Saccharomyces cerevisiae protein involved in plasmid maintenance is necessary for mating of MATa cells. J. Mol. Biol. 204, 593-606.

Pnueli, L. Hareven, D., Rounsley, S. D., Yanofsky, M. F. and Lifshitz, E. (1994). Isolation of the tomato AGAMOUS gene TAG1 and analysis of its homeotic role in transgenic plants. Plant Cell 6, 163-173.

Reinitz, J. and Levin, M. (1990). Control of the initiation of homeotic gene expression by the gap genes giant and tailless in Drosophila. Dev. Biol. 140, 57-72.

Schultz, E. A., Pickett, F. B. and Haughn, G. W. (1992). The FLO10 gene product regulates the expression domain of homeotic genes AP3 and PI in Arabidopsis flowers. Plant Cell 3, 1221-1227.

Schultz, E. A. and Haughn, G. W. (1993). Genetic analysis of the floral initiation process (FLIP) in Arabidopsis. Development 119, 745-765.

Schwarz-Sommer, Z., Huijser, P., Nacken, W., Saedler, H. and Sommer, H. (1990). Genetic control of flower development: homeotic genes of Antirrhinum Majus. Science 250, 931-936.

Smyth, D. R., Bowman, J. L. and Meyerowitz, E. M. (1990). Early flower development in Arabidopsis. Plant Cell 2, 755-767.

Shannon, S. and Meeks-Wagner, D. R. (1993). Genetic interaction that regulate inflorescence development in Arabidopsis. Plant Cell 5, 639-655. 
Sommer, H., Beltran, J. P., Huijser, P., Pape, H., Lonnig, W. E., Saedler, H. and Schwarz-Sommer, Z. (1992). Deficiens, a homeotic gene involved in the control of flower morphogenesis in Antirrhinum majus: the protein shows homology to transcription factors. EMBO J. 9, 605-613.

Tsuchimoto, S., van der Krol, A. R. and Chua, N. H. (1993). Ectopic expression of pMADS3 in transgenic petunia blind mutant. Plant cell 5, 843853.

van der Krol, A. R., Brunelle, A., Tsuchimoto, S. and Chua, N. H. (1993). Functional analysis of petunia floral homeotic MADS box gene PMADS1. Gene Dev. 7, 1214-1228.

Weigel, D., Alvarez, J., Smyth, D. R., Yanofsky, M.F. and Meyerowitz,
E.M. (1992). $L E A F Y$ controls floral meristem identity in Arabidopsis. Cell 69, 843-859.

Weigel, D. and Meyerowitz, E. M. (1993). Activation of floral homeotic genes in Arabidopsis. Science 261, 1723-1726.

Weigel, D. and Meyerowitz, E. M. (1994). The ABCs of floral homeotic genes. Cell 78, 203-209.

Yanofsky, M. F., Ma, H., Bowman, J. L., Drews, G. N., Feldmann, K. A. and Meyerowitz, E. M. (1990). The protein encoded by the Arabidopsis homeotic gene AGAMOUS resembles transcription factors. Nature 346, 35-40.

(Accepted 9 January 1995) 